\title{
What is the right scale for REDD? The implications of national, subnational and nested approaches
}

Arild Angelsen, Charlotte Streck, Leo Peskett, Jessica Brown and Cecilia Luttrell

\section{Key points}

- Three proposals on the geographical level or scale of REDD accounting and incentive mechanisms are under discussion: direct support to projects (subnational levels), direct support to countries (national level), or a hybrid ('nested') approach combining the two.

- A subnational or project approach allows for early involvement and wide participation and is attractive to private investors. However, it may suffer from leakage (increased emissions outside project boundaries) and cannot address the broader forces driving deforestation and forest degradation.

- A national approach allows pursuit of a broad set of policies, addresses domestic leakage and creates country ownership. In the short to medium term, however, a national approach will be feasible for only a few countries, as it does not work well in situations susceptible to governance failures; it may also be less likely to mobilise private investment or local government involvement.

- A nested approach is the most flexible mechanism. It allows countries to start REDD efforts through subnational activities and gradually move to a national approach, or for the coexistence of the two approaches in a system where REDD credits are generated by projects and governments, thus maximising the potential of both approaches. However, the nested approach presents the challenge of harmonisation between the two levels.

Reducing emissions from deforestation and forest degradation (REDD) is a proposed financial mechanism that would provide incentives for efforts to reduce forest sector emissions in developing countries. REDD could become part of an international climate agreement, currently under discussion within the United Nations Framework Convention on Climate
Change (UNFCCC). A key question in the debate concerns the level (scale) at which accounting should be done and incentives offered for REDD activities. Should international accounting be limited to subnational (or project) activities, or to reductions at the national level, or should they occur at both levels (nested approach)? The choice of the geographical 


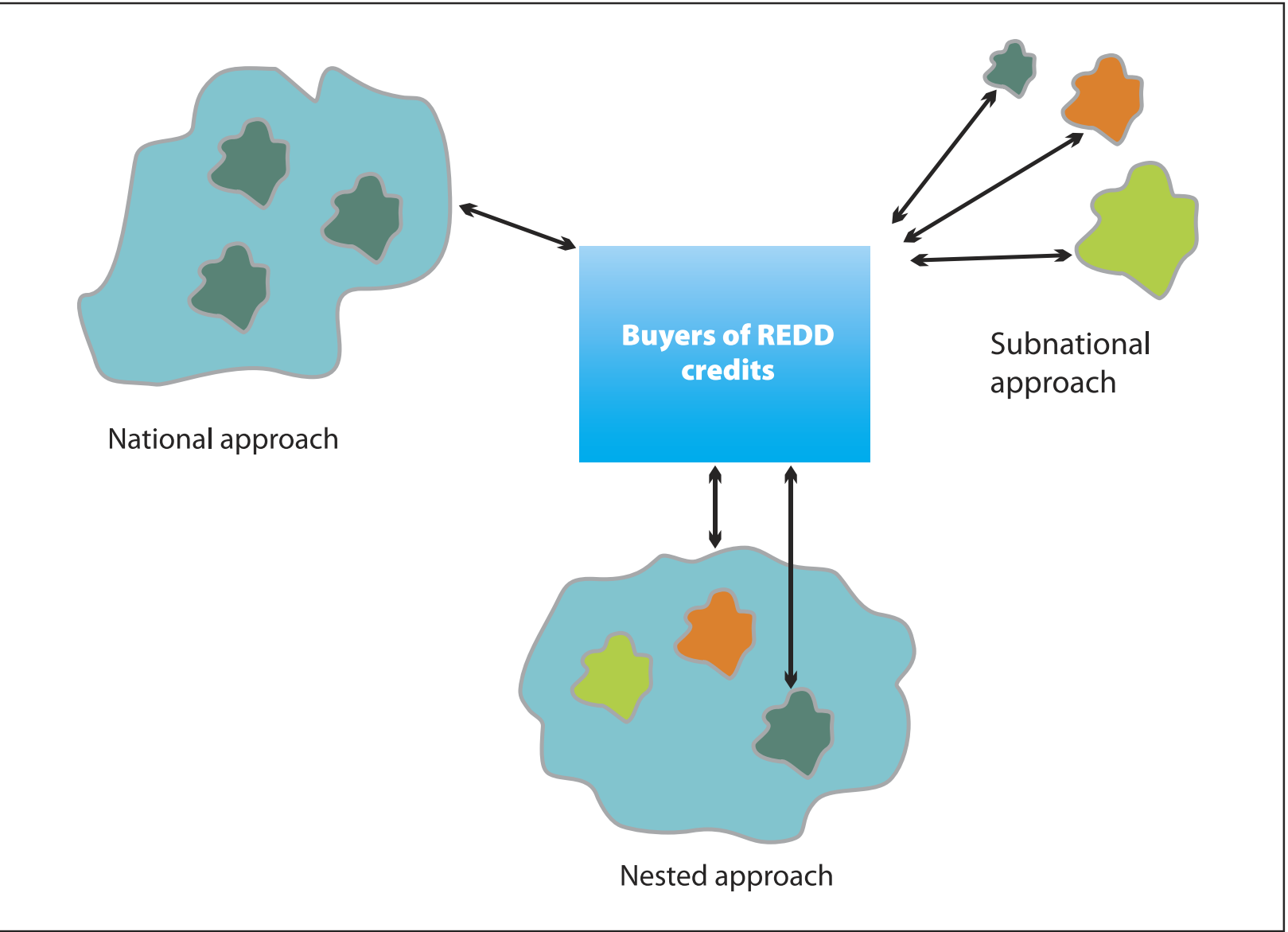

Figure 1.The three REDD accounting and crediting options (arrows indicate money from the international buyers, and information from the (subnational entities).

level or scale for accounting and crediting of REDD has profound implications for the effectiveness, efficiency and equity of the REDD mechanism (see Figure 1).

\section{Three options for the scale of REDD}

\section{Subnational approach}

Under a subnational approach, REDD activities would be implemented in a defined geographical area or at a project scale, by individuals, communities, NGOs, private companies or national or local governments. As with all the three approaches, crediting REDD activities would require internationally agreed rules for monitoring, reporting and verification (MRV), a system for payment and institutional arrangements at both the national level (a designated national authority or similar approving all projects) and the international level (a supervisory body and a centralised project and credit registry).

The modalities and procedures developed for the Clean Development Mechanism (CDM) under the Kyoto
Protocol could serve as a model for the institutional setup of subnational REDD. The CDM allows for developed (Annex l) countries to offset their own greenhouse gas emissions by supporting projects in developing countries that reduce emissions. In the forestry sector, only afforestation and reforestation $(\mathrm{A} / \mathrm{R})$ projects are currently eligible, and so far only one project has been approved. The CDM has proved more successful in other sectors, particularly in the energy sector, which had a primary market value of USD 7.4 billion in 2007 (Hamilton et al. 2008). Reasons for the slow progress of $A / R$ CDM projects include complex rules, methodologies and registration costs, which make transaction costs very high; the lack of transferability of the temporary credits assigned to projects; and the exclusion of credits from the EU Emission Trading System (ETS). The ETS is by far the largest carbon market, with a volume of USD 50 billion in 2007, or 78 per cent of the global carbon trade (Hamilton et al. 2008).

Another example of a subnational approach is the avoided deforestation projects operating in the voluntary carbon market. Transactions in the voluntary carbon market reached USD 330 million in 2007 


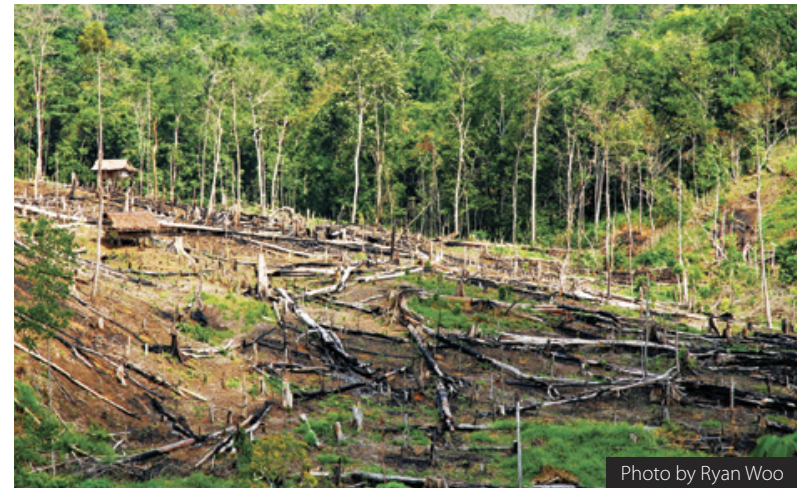

A national approach is better suited to address the broader forces of deforestation and degradation: clearing forest for agriculture, Riau, Indonesia.

(forestry-related projects comprising 18 per cent of the market), which was less than 5 per cent of the CDM primary market. Eighty per cent of the transactions on the voluntary carbon market involved private sector buyers (Hamilton et al. 2008).

Given the relative success of CDM in other sectors, its established institutional structure and the difficulties some countries may have in participating with a national approach to REDD, some Parties to the UNFCCC argue that a project-based mechanism should be included in the global REDD framework. Including REDD in CDM is also being discussed as part of the post-2012 negotiations under the Kyoto Protocol (Article 3.9), though it is recognised that the limited success of $A / R$ projects suggests that a project-based REDD approach cannot simply replicate the CDM model.

\section{National approaches}

Most country submissions to the UNFCCC advocate a national approach to REDD. This reflects past experience with project approaches, in which leakage and transaction costs have been a concern. The national approach also addresses sovereignty issues, and acknowledges that combating deforestation entails broad policy changes and thus has the potential to achieve larger-scale reductions.

Governments taking a national approach would establish a national system for MRV, and would be rewarded for emission reductions relative to an established reference level. Reductions would be rewarded through allocation of tradable carbon credits, by financial transfers from a global fund or other mechanisms. No direct credits would be issued internationally for activities that reduce emissions at the subnational level.

Consistent with its circumstances, each participating country would be responsible for implementing policies and measures to reduce emissions from deforestation and forest degradation over its entire territory in order to access international incentives. These might include a system to provide credits (payment for environmental services, or PES) to local communities.

\section{Nested approach}

Given the diverse national circumstances, some suggest integrating subnational activities into a national accounting framework through a 'nested' approach (first presented coherently by Pedroni et al. 2007). Countries would be able to start REDD activities at any level. Those that decide to initiate at the subnational level would be able to scale up to a national approach as they increase their capacities and improve their governance. Transition to a national approach would be mandatory, either within an agreed time frame or when an agreed percentage of forest area is covered by REDD projects, whichever comes first.

Although the transition to a national approach would be obligatory, it would still be possible to credit individual project activities within a national approach. The nested approach would therefore have two unique features. First, the ability to scale up over time from a subnational to a national approach. Second, the option for a country to account and receive international credits at both subnational and national levels simultaneously. Also, different countries could use different crediting mechanisms at the same time.

In a nested approach, procedures for MRV and reference levels would need to be harmonised between subnational and national levels. An arrangement for credit sharing between the two levels could be modelled on the existing Joint Implementation mechanism under the Kyoto Protocol. At the end of each accounting period, the country would have to

\section{Box 1: How a nested approach might work}

A project generates 1000 tonnes of carbon dioxide emission reductions during the accounting period. The country's overall reduction (carbon credits) is 5000 tonnes during the period. The 1000 tonnes already credited to the project have to be deducted from the national balance. In order to account for project-level leakage, MRV costs and the risk of non-permanence (higher emissions in the future), the government may retain a certain share of the carbon credits assigned to the project. Thus, the government and the project might agree that the project keeps 70 per cent of the credits produced while the government keeps 30 per cent. In this scenario, the project would keep 700 credits and the government 4300 credits. 
deduct all issued and committed subnational credits from national credits that reflect the country-wide emission reductions (see box 1). Should the national level fail to deliver carbon benefits, independently validated and verified subnational activities would still be credited.

\section{Assessment of the approaches}

\section{Effectiveness}

In terms of carbon effectiveness and emission reduction goals, the differences between the three options are apparent in three main dimensions: (i) ability to deal with leakage; (ii) overall level of participation, which will influence overall emission reduction achieved; and (iii) broad policy reforms, which will influence the depth, cost and permanence of reductions.

The geographical scope of the national and nested approaches is potentially much larger than the scope of the subnational approach, thereby addressing the problem of domestic leakage in the accounting and achieving greater effectiveness ( $\mathrm{M}$-Co, Consulting 2008). However, the current inability of most developing countries to participate under the national approach due to inadequate MRV infrastructure raises the problem of international leakage. Yet the flexibility of the nested approach should permit most countries to participate sooner, thus reducing (but not eliminating) international leakage.

Reforming land tenure and improving governance are examples of actions that could be key elements of a national REDD strategy. However, their effects would be difficult to trace to particular geographical areas, and such reforms would generally not fall within the scope of a subnational or project-based approach. Thus, national approaches are likely to encourage broader and more strategic policies, leading to deeper and longer-term emissions cuts.

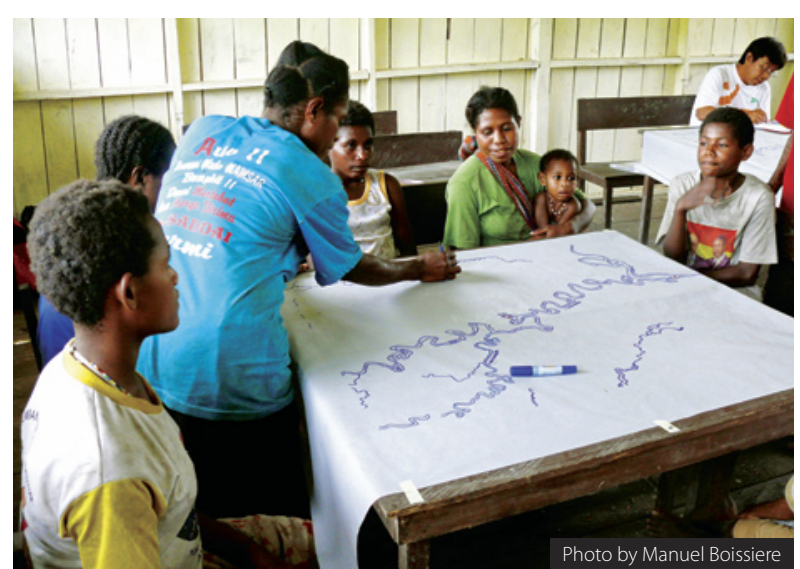

Subnational approach allows for wider local participation and may be more attractive to private investors: multi-disciplinary landscape assessment, West Papua, Indonesia
Private investors may be reluctant to buy emission reductions produced nationally, preferring to invest in more 'tangible' forests in project areas, which can be directly associated with emissions reductions and other benefits, such as biodiversity conservation and poverty reduction. They would also be less likely to invest in upfront payments at the national level, given their lack of control over host country risks. This could exacerbate problems of limited country participation.

\section{Efficiency}

The cost efficiency of different scale approaches to REDD is likely to be affected by three categories of costs: (i) costs of MRV; (ii) costs of implementing policies; and (iii) efficiency of opportunity cost payments.

Developing national infrastructure for MRV has significant economies of scale. This means that the national approach is likely to be more efficient in terms of cost per unit of carbon dioxide emission reduction or area covered. For example, a pure national approach would not necessarily require disaggregating data to regional or district levels, thus reducing the number of sample plots required for monitoring for example. The nested approach has higher costs as it requires both national coverage and subnational monitoring and accounting.

A second element affecting efficiency is the cost of REDD policy implementation. Implementing a system to credit subnational units (a national PES system) incurs costs in registering the project with centralised institutions; validation and verification; and administering contracts. The related economies of scale favour nationwide implementation. However, while a national system may have the potential to generate greater emissions reductions at lower costs, it could also result in greater inefficiencies through bureaucracy and corruption. A subnational approach may have higher overall transaction costs per unit of emission reduction, but it may be run more efficiently, given its smaller size and the likelihood of it being managed by private entities that have experience in carbon market mechanisms and that prioritise cost efficiency.

National approaches may include broad schemes reforms and many of these will be cheaper to implement than PES-type policies. In some cases, such reforms might even generate savings, such as removal of subsidies that stimulate deforestation and degradation.

The opportunity costs of forest conservation (typically the profit from agriculture and timber harvesting that could be generated from the land) vary greatly among those who hold rights to use forest. If rights holders could be compensated according to their specific opportunity costs, overall costs would be a 
substantially lower. In a study from Brazil, Börner and Wunder (2008) estimate that the cost savings of perfectly differentiated payments compared to uniform compensation is in the order of 45-75 per cent. Introducing differentiated payments might be more realistic in a subnational approach, possibly as part of a nested system, due to the high transaction costs of doing so in a national system. The difficulties experienced in excluding non-additional activities (leading to inefficient payments) can be seen in the national PES system in Costa Rica (Karousakis 2007). Differentiated payments are possible in a national system, but there is a trade-off between opportunity cost payments and transaction costs, and possibly also between opportunity cost payments and equity considerations, given that some of the poorest rights holders also have the lowest opportunity costs.

\section{Equity}

A regime allowing only national approaches to REDD could exclude most of the low-income countries because of their inadequate infrastructure for MRV and poor governance. Thus, the international flow of money could be skewed towards a few middleincome countries such as Brazil. However, subnational approaches might not necessarily perform better in this regard, as illustrated by the CDM experience. In 2007, some 73 per cent of all CDM credits sold were 'made in China' (Hamilton et al. 2008). This points to the need, irrespective of the scale approach chosen, for readiness activities to increase national capacity and institutions, and more generally to improve governance and accountability to ensure participation of the poorest countries.

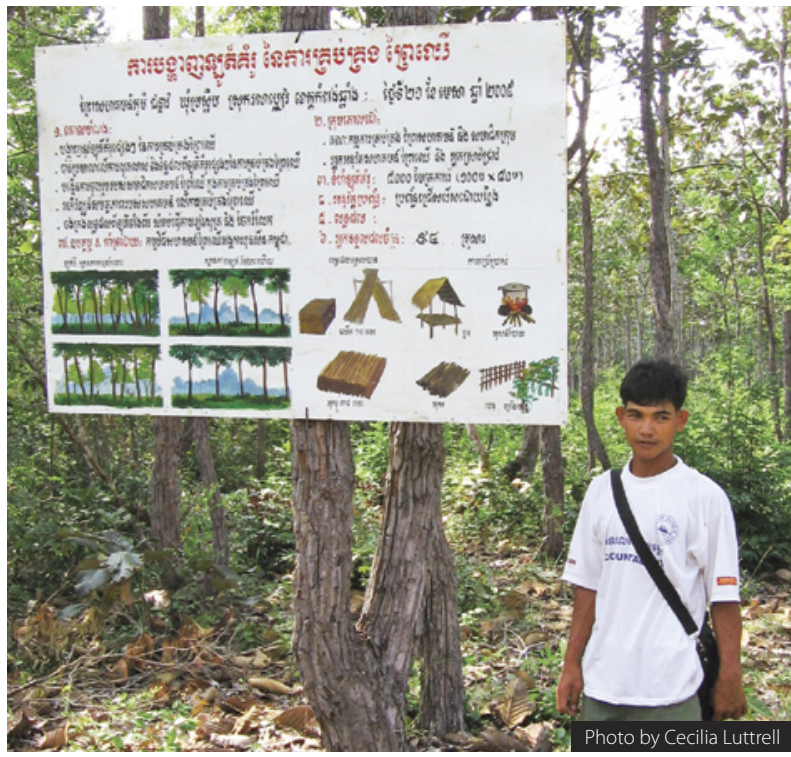

Nested approaches may be more flexible in responding to the needs of specific contexts: community forestry in Cambodia

In terms of intra-national equity, it is possible that a centralised national approach could limit the participation of rural communities in REDD design and implementation. This could result in inequitable sharing of benefits and the 'nationalisation' of carbon rights. Large new financial flows may increase the risk of corruption and state capture, preventing the benefits from reaching the poor. Governments also have a decidedly mixed track record in promoting inclusive decision making processes (Foti et al. 2008) and may have little incentive to ensure broad local participation in REDD. National approaches may thus risk generating inequitable outcomes resulting from inequitable

Table 1. Pros and cons of different approaches

\begin{tabular}{|c|c|c|c|}
\hline \multirow{2}{*}{ REDD model } & \multicolumn{3}{|c|}{ Criteria } \\
\hline & Effectiveness & Efficiency & Equity and co-benefits \\
\hline $\begin{array}{l}\text { Subnational } \\
\text { approach }\end{array}$ & $\begin{array}{l}+ \text { Broad short-term participation } \\
+ \text { Attractive to private funders } \\
\text { - Domestic leakage a problem } \\
\text { - Does not trigger the required policy } \\
\text { changes } \\
\text { - Weak involvement of host countries }\end{array}$ & $\begin{array}{l} \pm \text { MRV costs lower overall but higher } \\
\text { per } \mathrm{CO}_{2} \text { equivalent } \\
+ \text { Differentiated incentive payment } \\
\\
\text { possible: lowers costs }\end{array}$ & $\begin{array}{l}+\quad \text { Easier participation by poor countries } \\
\text { and those with weak governance } \\
+\quad \text { Can target poor domestic groups } \\
\text { and create more opportunities for } \\
\text { community participation }\end{array}$ \\
\hline $\begin{array}{l}\text { National } \\
\text { approach }\end{array}$ & $\begin{array}{l}+ \text { Broader set of policies pursued } \\
+ \text { Captures domestic leakage } \\
+ \text { Stronger host country ownership } \\
\text { - Unsolved issues of reference levels }\end{array}$ & $\begin{array}{l}+ \text { Lower MRV and transaction costs per } \\
\mathrm{CO}_{2} \text { equivalent } \\
+\quad \text { Low-cost (non-PES) policies available } \\
\text { - Potential for policy and governance } \\
\text { failure }\end{array}$ & $\begin{array}{cl}+ & \text { Potentially larger overall transfers } \\
+ & \text { Better alignment with national } \\
& \text { development strategies } \\
\text { - } & \text { Favours middle-income countries } \\
\text { - } & \text { Risk of high level and elite capture } \\
& \text { ('nationalisation' of carbon rights) }\end{array}$ \\
\hline $\begin{array}{l}\text { Nested } \\
\text { approach }\end{array}$ & $\begin{array}{l}+ \text { Combines strengths of other two } \\
\text { approaches } \\
+ \text { Flexibility based on national } \\
\text { circumstances } \\
+ \text { Potential for larger overall transfers } \\
\text { - Unsolved issues of reference levels }\end{array}$ & $\begin{array}{l}\text { + Both differentiated compensation } \\
\text { pay and low-cost broad policies } \\
\text { - High MRV costs (which requires } \\
\text { disaggregated nation al data) } \\
\text { - Challenge to harmonise between } \\
\text { national and sub national }\end{array}$ & $\begin{array}{l}+\quad \text { Increased country participation and } \\
\text { larger transfers to poor countries } \\
+ \text { Possible to target poor groups }\end{array}$ \\
\hline
\end{tabular}


processes. On the other hand, a national approach may be better aligned with national development strategies, possibly bringing long-term development benefits. Smaller-scale subnational and nested approaches may be more flexible in responding to the needs of specific contexts. Evidence from some carbon forestry projects suggests that they can increase local capacities, participatory decision making and community-based resource management (Corbera 2005). However, private investors and conservation NGOs have a mixed track record when it comes to factoring community concerns into their projects. Carbon markets are driven primarily by global climate protection objectives, rather than local socio economic objectives (May et al. 2004). Both subnational and national approaches are likely to face challenges in this area, but the drivers shaping the level of participation, along with the actors and processes involved, will be different.

\section{Conclusion}

All three approaches have advantages, disadvantages and tradeoffs in terms of carbon effectiveness, cost efficiency and equity. Nevertheless, a nested system appears to give the best returns based on these criteria. It could allow a country to engage in REDD with a project or national approach, ensuring broader international participation and thereby larger overall emission reductions in the short term. The limitations of subnational approaches (and domestic leakage in particular) are taken into account through the imposed time limit for adoption of a national approach, allowing countries time to establish the infrastructure, institutions and governance needed for national-level crediting. The nested approach therefore provides flexibility and an appreciation of the diversity of national circumstances.

\section{References}

Börner, J. and Wunder, S. 2008 Paying for avoided deforestation in the Brazilian Amazon: from cost assessment to scheme design. International Forestry Review 10(3): 496-511.

Corbera, E. 2005 Bringing development into carbon forestry markets: challenges and outcomes of small-scale carbon forestry activities in Mexico. In: Murdiyarso, D. and Herawati, H. (eds.) Carbon forestry: who will benefit? 42-56. CIFOR, Bogor, Indonesia.

Foti, J., de Silva, L., Werksman, J., Shaffer, L., Talbot and J. McGray, H. 2008 Voice and choice: opening the door to environmental democracy. World Resources Institute.

Hamilton, K., Sjardin, M., Marcello, T. and Xu, G. 2008 Forging a frontier: state of the voluntary carbon Markets. 2008. Ecosystem Market Place and New Carbon Finance, San Francisco and London.

Karousakis, K. 2007 Incentives to reducing emissions from deforestation: lessons learned from Costa Rica and Mexico. OECD, Paris. P. 50.

May, P.H., Boyd, E., Viega, F. and Chang, M. 2004 Local sustainable development effects of forest carbon projects in Brazil and Bolivia. International Institute of Environment and Development, London, UK.

M-Co Consulting. 2008 Review and assessment of options for reducing emissions from deforestation in developing countries. Government of New Zealand, Ministry of Agriculture and Forestry, Wellington.

Pedroni, L., Streck, C., Estrada, M. and Dutschke, M. 2007 The 'nested approach'. A flexible mechanism to reduce emissions from deforestation. CATIE, Turrialba, Costa Rica.
For further information, please contact: Arild Angelsen arild.angelsen@umb.no Charlotte Streck c.streck@climatefocus.com Leo Peskett I.peskett@odi.org.uk Jessica Brown j.brown@odi.org.uk Cecilia Luttrell c.luttrell@cgiar.org

For general inquiries: cifor@cgiar.org


CLIMATEFOCUS

Project funding was received from the David and Lucile Packard Foundation

Center for International Forestry Research (CIFOR) advances human well-being, environmental conservation, and equity by conducting research to inform policies and practices that affect forests in developing countries. CIFOR is one of 15 centres within the Consultative Group on International Agricultural Research (CGIAR). CIFOR's headquarters are in Bogor, Indonesia. It also has offices in Asia, Africa and South America. CIFOR works in over 30 countries worldwide and has links with researchers in 50 international, regional and national organisations. www.cifor.cgiar.org 